\title{
Effectiveness of electrical stimulation on rehabilitation after ligament and meniscal injuries: a systematic review
}

\author{
Efetividade da estimulação elétrica na reabilitação pós-lesões ligamentares e \\ meniscais: uma revisão sistemática
}

\author{
Aline Mizusaki Imoto', Stella Peccin", Gustavo Jerônimo Melo Almeida"', Humberto Saconato"v , Álvaro Nagib Atallah \\ Brazilian Cochrane Centre, São Paulo, Brazil
}

IPhD. Postgraduate Program on Internal Medicine and Therapeutics, Universidade Federal de São Paulo (Unifesp), São Paulo, Brazil. "PhD. Supervising Professor of the Postgraduate Program on Internal Medicine and Therapeutics, Universidade Federal de São Paulo (Unifesp), São Paulo; and Head of the Department of Movement Sciences, Universidade Federal de São Paulo, Campus Baixada Santista, São Paulo, Brazil. "'PhD. Physiotherapist, Department of Physical Therapy, University of Pittsburgh, Pittsburgh, United States.

"vphD, Adjunct Professor, Department of Clinical Medicine, Universidade Federal do Rio Grande do Norte (UFRN), Natal, Rio Grande do Norte, Brazil.

vphD. Titular Professor, Department of Internal Medicine, Universidade Federal de São Paulo (Unifesp), São Paulo, Brazil.

\section{KEY WORDS:}

Electric stimulation therapy.

Rehabilitation.

Knee joint.

Knee injuries

Physical therapy modalities.

\section{PALAVRAS-CHAVE:}

Terapia por estimulação elétrica.

Reabilitação.

Articulação do joelho.

Traumatismos do joelho

Modalidades de fisioterapia.

\begin{abstract}
CONTEXT AND OBJECTIVE: Electrical stimulation (ES) is widely used to strengthen muscles following ligament and meniscal injuries. The aim of this study was to evaluate the effectiveness of ES for rehabilitation after soft tissue injuries of the knee treated surgically or conservatively.

DESIGN AND SETTING: Systematic review at the Brazilian Cochrane Center.

METHODS: We searched the Cochrane Central Register of Controlled Trials (2010, Issue 12), Medline (Medical Analysis and Retrieval System Online) via PubMed (1966 to December 2010), Embase (Excerpta Medica database, 1980 to December 2010), Lilacs (Literatura Latino-Americana e do Caribe em Ciências da Saúde, 1982 to December 2010), and PEDro (Physiotherapy Evidence Database, 1929 to December 2010). The studies included were randomized controlled trials using ES to increase muscle strength for rehabilitation of patients with soft tissue injuries of the knee. Two authors independently evaluated studies for inclusion and performed data extraction and methodological quality assessment.

RESULTS: Seventeen studies evaluating ES after anterior cruciate ligament reconstruction and two studies evaluating ES after meniscectomy were included. There was a statistically significant improvement in quadriceps strength through ES (mean difference, MD: -32.7; 95\% confidence interval, Cl: -39.92 to -25.48; $n=56$ ) and in functional outcomes (MD $-7 ;-12.78$ to $-1.22 ; n=43$ ) six to eight weeks after surgical reconstruction of the anterior cruciate ligament.

CONCLUSION: There is evidence that ES coupled with conventional rehabilitation exercises may be effective in improving muscle strength and function two months after surgery.
\end{abstract}

\section{RESUMO}

CONTEXTO E OBJETIVO: A estimulação elétrica (ES) é amplamente utilizada para fortalecimento muscular após lesões ligamentares ou meniscais do joelho. O objetivo deste estudo foi avaliar a efetividade da ES na reabilitação de lesões de tecidos moles do joelho tratadas de forma cirúrgica ou conservadora. TIPO DE ESTUDO E LOCAL: Revisão sistemática no Centro Cochrane do Brasil.

MÉTODOS: Realizamos uma busca no Cochrane Central Register of Controlled Trials (2010, Issue 12), Medline (Medical Analysis and Retrieval System Online) via PubMed (1966 até dezembro 2010), Embase (Excerpta Medica Database, de 1980 até dezembro 2010), Lilacs (Literatura Latino-Americana e do Caribe em Ciências da Saúde, de 1982 até dezembro de 2010), and PEDro (Physiotherapy Evidence Database, de 1929 até dezembro de 2010). Os estudos incluídos foram ensaios clínicos randomizados que utilizaram a ES com o objetivo de aumento de força muscular na reabilitação de pacientes com lesões de tecidos moles. Dois autores avaliaram os estudos para inclusão de forma independente e realizaram a extração de dados e avaliação da qualidade metodológica.

RESULTADOS: Dezessete estudos incluídos utilizaram a ES após a reconstrução do ligamento cruzado anterior e dois estudos após meniscectomia. Houve melhora estatisticamente significante na força do quadríceps através da ES (diferença média, MD -32.7; 95\% intervalo de confiança, IC -39.92 to -25.48; n = 56) e nos desfechos funcionais (MD -7; -12.78 to $-1.22 ; n=43$ ), seis a oito semanas após cirurgia de reconstrução do ligamento cruzado anterior.

CONCLUSÃO: Há evidências de que a ES combinada a exercícios de reabilitação convencional pode ser efetiva na melhora da força muscular e função dois meses após cirurgia. 


\section{INTRODUCTION}

Knee injuries can be considered to be a modern epidemic. ${ }^{1}$ They are more common among people between 10 and 29 years of age and occur more often among men (57\%). Soft tissue injuries of the knee most frequently involve the menisci or knee ligaments. The incidences of these injuries are 0.3 and 0.7 per 1000 individuals/ year, respectively. ${ }^{1}$ The anterior cruciate ligament (ACL) is the ligament most frequently damaged, and the medial meniscus is the most frequently damaged meniscus. One study investigating associations between ACL and meniscal injury ${ }^{2}$ found that $86 \%$ of the patients with ACL insufficiency had an associated meniscal injury, while $58 \%$ presented this association in another study. ${ }^{3}$

In general, knee soft tissue injuries occur when the knee twists while bearing weight. The injury severity depends on the excess movement and force on the knee joint.

Muscle wasting and weakness are well-known effects following joint surgery and immobilization. Improvement of muscle strength is a major goal to be achieved early during rehabilitation. ${ }^{4}$ For example, atrophy and weakness quickly develop in the quadriceps muscle after ACL reconstructive surgery. ${ }^{5,6}$ Five to six weeks of immobilization following serious ligament injury or surgery induces significant changes in type 1 muscle fibers in the quadriceps ${ }^{7,8}$ and $60 \%$ to $80 \%$ reduction in isometric quadriceps strength. ${ }^{9}$ Muscle strength is important for recovering physical function, and compromised thigh muscle strength has been shown to be associated with abnormalities of walking velocity, stride length and pace. ${ }^{10}$

Avoidance of isolated use of the knee extensor muscle, in order to protect the newly made ligament, and time $e^{11,12}$ are the two main requirements in the rehabilitation process. Rehabilitation may include exercises and electrostimulation (ES) to improve quadriceps strength. ${ }^{13,14}$ ES is recommended as an adjunct treatment for quadriceps strengthening after anterior cruciate ligament reconstruction and has also been shown to improve quadriceps femoral torque produced after ligament knee surgery. ${ }^{15,16}$ The most frequently used currents are: alternating current (2500 $\mathrm{Hz}$ ) and pulsed biphasic asymmetric rectangular current. The choice of electrical current must be based on the capacity of electrical stimulation to produce an effective contraction. ${ }^{17}$ ES is widely used to strengthen muscles after soft tissue injuries of the knee such as ligament and meniscal injuries, and after surgery to treat these conditions, such as anterior cruciate ligament reconstruction. It is therefore important to conduct a systematic review to assess the effectiveness of electrical stimulation for improving the strength of muscles following soft tissue injuries of the knee, treated conservatively or surgically.

\section{OBJECTIVES}

To assess the effectiveness of ES for rehabilitation after soft tissue injuries of the knee (anterior cruciate, posterior cruciate, lateral and medial ligament and meniscal injuries), treated surgically or conservatively.

\section{METHODS}

Types of studies included: This review included randomized or quasi-randomized controlled trials.

Types of participants: The patients included in this review were 14 years old or over, with soft tissue injuries of the knee (acute or chronic injury of the anterior or posterior cruciate ligament, medial or lateral collateral ligament, menisci, alone or in combination), treated surgically or conservatively.

Types of interventions: The rehabilitation protocols that were assessed involved ES as a component of a rehabilitation program after soft tissue injuries of the knee.

Controls: The controls received no treatment, placebo, other physical intervention or conventional rehabilitation.

\section{Types of outcome measurements}

Primary outcomes: The primary outcomes were muscle strength; functional outcomes (e.g. self-selected walking speed, number of participants using crutches or number of participants who did not progress to the treadmill); pain, as measured using a visual analogue scale; and functional scales, e.g. the activities of daily living (ADL) scale and Lysholm score.

Secondary outcomes: The secondary outcomes were range of motion; KT-1000 arthrometer results; subjective and objective laxity/instability of the knee; swelling; and time taken to return to work, at pre-injury level of activity.

\section{Search strategy to identify studies}

We searched the Cochrane Central Register of Controlled Trials (Cochrane Library 2010, Issue 12); Medline (Medical Analysis and Retrieval System Online) via PubMed (1966 to December 2010); Embase (Excerpta Medica Database; 1980 to December 2010); Lilacs (Literatura Latino-Americana e do Caribe em Ciências da Saúde; available at http://bases.bvs.br, from 1982 to December 2010); Cumulative Index to Nursing and Allied Health Literature (CINAHL; 1982 to December 2010); PEDro (Physiotherapy Evidence Database, 1929 to December 2010), at http://www.pedro.fhs.usyd.edu.au/index.html); and the reference lists of studies. We also contacted study authors and experts in order to identify unpublished data. No language restrictions were applied.

The search strategies for randomized controlled trials in PubMed, Embase and Lilacs were combined with subject-specific search terms (electrical stimulation terms and knee injury terms). The strategies of Medline via PubMed were adapted for other databases. The PubMed search strategy was the following: (knee AND (injur* OR ligament* OR tendon* OR (soft tissue) OR menisc $\left.{ }^{\star}\right)$ AND ((electric ${ }^{\star}$ AND stimulation) OR (neuro 
AND muscle AND stimulation)) AND(randomized controlled trial [pt] OR controlled clinical trial [pt] OR randomized controlled trials $[\mathrm{mh}$ ] OR random allocation [mh] OR double-blind method [mh] OR single-blind method [mh] OR clinical trial [pt] OR clinical trials $[\mathrm{mh}]$ OR ("clinical trial" $[\mathrm{tw}])$ OR $\left((\operatorname{singl})^{\star}[\mathrm{tw}]\right.$ $\mathrm{OR}_{\text {doubl }}{ }^{*}[\mathrm{tw}]$ OR trebl${ }^{\star}[\mathrm{tw}]$ OR tripl $\left.{ }^{*}[\mathrm{tw}]\right)$ AND $\left(\mathrm{mask}^{*}[\mathrm{tw}]\right.$ OR blind* $[\mathrm{tw}]))$ OR ( placebos $[\mathrm{mh}]$ OR placebo* $[\mathrm{tw}]$ OR ran$\mathrm{dom}^{\star}[\mathrm{tw}]$ OR research design [mh:noexp] OR comparative study [mh] OR evaluation studies [mh] OR follow-up studies [mh] OR prospective studies [mh] OR control ${ }^{\star}[\mathrm{tw}]$ OR prospectiv ${ }^{*}[\mathrm{tw}]$ OR volunteer ${ }^{\star}[\mathrm{tw}]$ ) NOT (animals [mh] NOT human [mh]).

\section{Methods}

Two authors independently selected trials for inclusion. Any disagreements were resolved through consultation with a third author.

Two authors independently extracted the data. Data relating to methodological issues, participants' characteristics, interventions and outcome measurements were extracted using a standard extraction form.

Two authors independently assessed trial quality using the Delphi list ${ }^{18}$ (Table 1). The numbers of positive answers to the questions in the questionnaire were expressed as percentages).

\section{Data analysis}

For dichotomous data, the relative risk (RR) and 95\% confidence interval (CI) were calculated. Continuous outcomes were analyzed using the mean and standard deviation of endpoint measurements, in order to generate the mean difference (MD) and 95\% CI. The Rev Man 5 statistical package supplied by the Cochrane Collaboration was used to perform metaanalyses.

The presence of heterogeneity was investigated by means of the chi-square test and the $\mathrm{I}_{2}$ test. The heterogeneity was considered statistically significant when $\mathrm{I}_{2}$ was greater than $50 \%$ and the P-value was less than $<0.10(<10 \%)$.

Table 1. Delphi list ${ }^{18}$

\begin{tabular}{|c|c|}
\hline \multicolumn{2}{|l|}{ Delphi list } \\
\hline 1. Allocation & \\
\hline a) Was the method of randomizatio & Yes/No/Don't know \\
\hline b) Was the method of random allocatio & Yes/No/Don't know \\
\hline $\begin{array}{l}\text { 2. Were the groups similar at baseline regarding the } \\
\text { most important prognostic characteristics? }\end{array}$ & Yes/No/Don't know \\
\hline 3. Were both inclusion and exclusion criteria specified? & Yes/No/Don't know \\
\hline 4. Was the outcome assessor blinded? & Yes/No/Don't know \\
\hline 5. Was the care provider blinded? & Yes/No/Don't know \\
\hline 6. Was the patient blinded? & Yes/No/Don't know \\
\hline $\begin{array}{l}\text { 7. Were point estimates and measures of variability } \\
\text { presented for primary outcome measure(s)? }\end{array}$ & Yes/No/Don't know \\
\hline $\begin{array}{l}\text { 8. Did the analysis include an 'intention-to-treat' } \\
\text { analysis? }\end{array}$ & Yes/No/Do \\
\hline
\end{tabular}

\section{RESULTS}

The results from the search were that the following were identified: 177 studies in Medline, of which 21 were selected for evaluation; 145 studies in Embase, of which 18 were selected for evaluation; 51 in PEDro, of which three were selected for evaluation; 33 in the Cochrane Controlled Trials Register, of which 21 were selected for evaluation; and five in Lilacs, of which none were selected. After taking into account the duplicated references in different databases, 19 studies were included and two were excluded.

\section{Description of the studies included}

The sample sizes ranged from eight to 110 patients. Participants' ages ranged from 14 to 44 years. Most of the studies included (described in Table 2) involved patients undergoing ACL reconstruction. Two involved patients undergoing partial meniscectomy. These studies assessed the effectiveness of ES alongside rehabilitation programs to increase muscle strength, and ES was compared with: conventional exercises without ES and with different frequencies of ES; pulsed electromagnetic stimulation; and biofeedback therapy. The main outcome was muscle strength, which was assessed using an isokinetic dynamometer. Other outcomes assessed included: knee function questionnaires, KT-1000 arthrometer results, number of participants using crutches, number of participants whose rehabilitation did not progress to the use of a treadmill, walking velocity and stand time for the leg involved. Outcome measurements (isokinetic evaluation) were made between 1 and 52 weeks after surgery, and the isokinetic protocol involved differences in muscle contraction (isometric or isokinetic), test velocity and knee isometric test angle.

\section{Excluded studies}

The studies that were excluded ${ }^{19,20}$ are presented in Table 3 .

\section{Methodological quality of the studies included (Table 4)}

The studies that were included presented some methodological flaws. None of the studies described concealment of allocation at the time of randomization. Among the studies with drop outs, ${ }^{13-15,21,22}$ only Fitzgerald et al. ${ }^{15}$ mentioned intentionto-treat analysis. The baseline participant characteristics were well described and the groups were comparable. The interventions and outcomes were well defined and described. Blinded outcome assessment was reported in four studies. ${ }^{15,21,23,24}$ None of the studies included reported sample size calculations.

\section{Results from comparisons}

\section{Comparison 1: conventional rehabilitation with and without ES}

\section{Isometric quadriceps peak torque}

At four weeks after surgery, according to Lieber et al., ${ }^{25}$ the magnitude of the increase in isometric quadriceps torque was not 
Table 2. List of studies about electrical stimulation (ES) included in this review

Anderson et al. ${ }^{28}$ Inclusion criteria: patients with cruciate ruptures after

Setting: surgery

Nashville, $\quad$ Age (mean) and sex:

Tennessee, USA - group 1:20 years, 17 male and 2 female - group 2: 23 years, 10 males and 8 females - group 3: 20.4 years, 11 males and 9 female - group 4: 19.8 years, 16 males and 4 female - group 5: 22.8 years, 11 males and 8 females

Buhmann et al. ${ }^{26}$

Setting:

Göttingen

Germany

Inclusion criteria: patients with cruciate ruptures after surgery

Age:

- group 1: 18-47 years

- group 2: 21-43 years

- group 3: 20-44 years

Currier et al..$^{33}$

Setting:

University of

Kentucky, USA
Sample: 17

Inclusion criteria: anterior cruciate ligament reconstruction, age ranging from 15 to 39 years
Delitto et al. ${ }^{23}$

Setting:

Washington

University

Medical School,

USA

Draper and

Ballard ${ }^{32}$

Setting:

Knoxville

Orthopedic

Clinic, USA

Eriksson and

Häggmark ${ }^{28}$

Setting:

Stockholm

Sweden

Fitzgerald et al. ${ }^{15}$

Setting: USA

ainey et al. ${ }^{35}$

Setting: General

and Marine

Hospital, Owen

Sound, Canada

\section{Lieber et al ${ }^{25}$}

Setting:

San Diego,

California, USA

Paternostro-

Sluga et al.

Setting: Austria

Inclusion criteria:

Anterior cruciate ligament reconstruction

Sample: 49
Inclusion criteria: anterior cruciate ligament reconstruction and age between 19 to 44 years. Sample: 20

Inclusion criteria: between 15 and 44 years. ACL reconstruction.

Exclusion criteria: collateral ligament, posterior cruciate ligament injury or osteotomy.

Sample: 30

Inclusion criteria: patients with cruciate ruptures after surgery, with age between 20 and 40 years

Inclusion criteria: 14 years and above.

Exclusion criteria: rehabilitation in another setting Sample size: 31, underwent anterior cruciate ligament reconstruction.

Inclusion criteria: patients underwent meniscectomy surgery

Inclusion criteria: surgical reconstruction of the anterior cruciate ligament within previous 2-6 weeks and the ability to position the knee in $90^{\circ}$ flexion.

Sample: 40 men and women, $15-44$ years
Group 1: knee immobilizer in extension + quadriceps exercise

Group 2: knee immobilizer in extension + quadriceps exercise + TENS

Group 3: knee immobilizer in $60^{\circ}$ flexion+ quadriceps exercise + TENS

Group 4: knee immobilizer in $60^{\circ}$ flexion + quadriceps exercise + ES $10 \mathrm{hrs}$. a day

Group 5: knee immobilizer in $60^{\circ}$ flexion+ quadriceps exercise + TENS +

CPM (35-70०)

ES parameters:

F: $35 \mathrm{~Hz}$, pulse width of 150 microsec. Time on: $10 \mathrm{sec}$ and time off: $110 \mathrm{sec}$, for 3 months. Intensity: 65 to $100 \mathrm{~mA}$

Group 1: functional aftercare immediately after surgery consisting of therapeutic exercises and physiotherapy

Group 2: ES from day 7 after surgery, additionally to the therapeutic exercises and physiotherapy

Group 3: as group 2 and additionally, isokinetic training from week 9 onwards after surgery.

ES parameters:

- F: $50 \mathrm{~Hz}$, time on: $10 \mathrm{sec}$ and time off: $20 \mathrm{sec}, 30$ minutes

Isokinetic training parameters: 10 contractions at $60 \% \mathrm{~s}, 120 \% \mathrm{~s}$ and $180 \% \mathrm{~s}$

Sequential allocation: NMES or NMES and PEMF groups.

Standard ACL protocol that included range of motion, muscle setting, straight leg raise, and ambulation exercises during the first 6 weeks after surgery. NMES: $2500 \mathrm{~Hz}$ delivered in 50 bursts per second with a 10-ms "on" time and a 10-ms "off' time. Each induced contraction lasted 15 seconds (5-sec ramp on), followed by 50 seconds off for $10 \mathrm{n}$ contractions per session.

The NMES and PEMF was administered with physical therapy in the fourth and each succeeding session as outpatient treatment, three times per week for 5 weeks (total $=6$ weeks, 18 NMES and NMES/ PEMF treatments, two assessments).

1. $E S(n=10)$

- F: $2500 \mathrm{~Hz} / 50 \mathrm{~Hz}, 5$ days a week, for 3 weeks.

- Repetitions: 15, time on: $15 \mathrm{sec}$, time off: $50 \mathrm{sec}$.

2. Control Group $(n=10)$ : conventional rehabilitation.

Intervention: 6 weeks after surgery

1. $E S(n=15): F: 35 H z$, time on: $10 \mathrm{sec}$, time off: $20 \mathrm{sec}$

2. Biofeedback $(n=15)$

All patients underwent isometric quadriceps training

Group $1(n=4)$ :

ES, F: $200 \mathrm{~Hz}$, time on: $5-6 \mathrm{sec}$ and time off: $5 \mathrm{sec}$, for $1 \mathrm{hr}, 5$ days a week for 4 weeks

Group $2(n=4)$ : conventional protocol

1. ES group $(n=17)$

F: $2500 \mathrm{~Hz}$, pulsed at $75 \mathrm{~Hz}$, time on: $10 \mathrm{sec}$, time off: $50 \mathrm{sec}$, 2 days a week

10 repetitions. Total time: $11-12 \mathrm{~min}$.

2. Control group $(n=14)$

Conventional Rehabilitation.

Group 1: exercise alone followed by exercise plus stimulation, then they reverted to exercise alone, finishing with exercise plus stimulation.

Group 2: performed the reverse of the training of group 1.

They trained five times a week for the first two weeks and three times a week for the following four weeks.

ES characteristics: $4000 \mathrm{~Hz}$, pulsed at $100 \mathrm{~Hz}$, four electrodes.

Group 1: exercise

Group 2: exercise +

ES: 10 sec on and 20 sec off

Frequency: $50 \mathrm{~Hz}$

pulse duration: 250 microsec

Duration: 4 weeks

All the subjects were allowed to participate in a home program

1. ES + exercises

Program 1: F: $30 \mathrm{~Hz}$, time on: $5 \mathrm{sec}$, time off: $15 \mathrm{sec}$, 12 repetitions.

Program 2: F: $50 \mathrm{~Hz}$, time on: $10 \mathrm{sec}$, time off: $50 \mathrm{sec}$, 12 repetitions.

2. TENS + Exercises

$\mathrm{F}: 100 \mathrm{~Hz}, 30$ minutes, sensitive threshold.

Six weeks of intervention.

One control group (exercises).

1. ES group:

- F: $20 \mathrm{~Hz}$, time on: $15 \mathrm{sec}$, time off: $10 \mathrm{sec}$, total time: $60 \mathrm{~min}$.

2. ES (different frequency):

F: $80 \mathrm{~Hz}$, time on: $15 \mathrm{sec}$, time off: $75 \mathrm{sec}$, total time: $60 \mathrm{~min}$. 
Ross et al. ${ }^{29} \quad$ Inclusion criteria: underwent $A C L$ reconstruction

Setting: Ohio,

USA

Age: $27.1+4.89$ (CK chain) and 28.4+5.91

exclusion criteria: meniscal and ligament injuries associated
All patients performed isometric quadriceps training for 1 week postoperatively. CK chain group:

Rehabilitation with CK chain exercises

ES group:

F: $50 \mathrm{~Hz}$, time on: $15 \mathrm{~s}$, time off: $35 \mathrm{~s}$, for 6 weeks

Group 2: instruction in isometric co-contraction of the thigh muscles

Duration: 6 postoperative weeks

Group 1: Daily standardized postoperative exercise program.

Group 2: ES: $25 \mathrm{~Hz}$ or $1100 \mathrm{~Hz} 6$ times a day, $30 \mathrm{~min}$.

CT scan

Assessment: Before operation and 2 weeks, 6 weeks and 12 weeks afterwards.

1. ES group: 6 weeks, F: $40 \mathrm{~Hz}$, T on: $10 \mathrm{sec}$, T off: $30 \mathrm{sec}$

2. Exercise group: conventional rehabilitation.

1. ES group: 4 weeks, F: 50 Hz, T on: $110 \mathrm{sec}$, T off: $20 \mathrm{sec}$

2. Exercise group: conventional rehabilitation.

1. ES group: F: $2500 \mathrm{~Hz}$, T on: $15 \mathrm{sec} .$, T off: $50 \mathrm{sec}$.

2. Exercise group: conventional rehabilitation.

Duration of intervention: 6 weeks.

Setting: Boston,

USA

Snyder-Mackler

et al. ${ }^{24}$

Setting:

Delaware,

Pittsburgh

St. Louis,

Germantown

USA
Inclusion criteria: age: 15 to 43 years; diagnosis: $A C L$ reconstruction with Achilles tendon graft $(n=18)$, patellar-ligament allograft $(n=10)$, semitendinosus and gracilis tendons $(n=7)$, autologous patellarligament $(n=75)$.

Exclusion criteria: none reported
All patients were managed three times a week, from the first to sixth postoperative week.

Group 1: High-intensity ES: f: $2500 \mathrm{~Hz}$ at a burst rate of 75 bursts per

second, Time on: $11 \mathrm{~s}$, Time off: $120 \mathrm{~s}$, number of contractions: 15

Group 2: high volitional exercise, three times a week, number of

contractions: 15 positioned sitting with the knee in $60^{\circ}$ of flexion on

isokinetic dynamometer.

Group 3: low-intensity ES four times a day, five days a week

Time on: $15 \mathrm{~s}$, time off: $50 \mathrm{~s}$, frequency: $55 \mathrm{~Hz}$

Group 4: The patients received the treatment of groups 1 and 3. They did a

combination of high and low-intensity ES.

1. Exercise group: ankle exercises, quadriceps isometric contractions, hip abduction.

2. ES group: F: $30 \mathrm{~Hz}$., T on: $6 \mathrm{sec}$, T off: $10 \mathrm{sec}$.

ES group: ES to the quadriceps 10 minutes, 5 times a week, frequency: 2500

$\mathrm{Hz}$, pulsed at $50 \mathrm{~Hz}, 15 \mathrm{sec}$ of contraction and $50 \mathrm{sec}$ of resting.

Control group: quadriceps and hamstring isometrics and an isotonic

progressive resistance program 3 times a week.

$\begin{array}{ll}\text { Setting: } & \text { patients } \\ \text { California, USA } & \text { Sex: } 3 \text { females and } 18 \text { males }\end{array}$

Sample: 23

$\begin{array}{ll}\text { Lossing et al. } & \\ \text { Setting: Sweden } & \text { Age: } 18 \text { to } 28 \text { years. }\end{array}$

Williams et al. ${ }^{34}$ Inclusion criteria: post-arthroscopic meniscectomy

Age: range 18 to 45 years, mean 33 years

$\mathrm{ACL}=$ anterior cruciate ligament; TENS = transcutaneal electrical nerve stimulation; NMES = neuromuscular electrical stimulation; PEMF = pulsed electromagnetic field CK $=$ closed kinetic.

Table 3. Excluded studies

Franke et al. ${ }^{19}$

Retrospective study

Hörster et al. ${ }^{20}$

Only electromyography (EMG) assessment

significantly different between the groups. At six, nine and twelve weeks after the operation, the decrease in isometric quadriceps torque in the stimulation group during immobilization was significantly less than that of the group without stimulation (without correlatable data). At six weeks after surgery, Delitto et al., ${ }^{23}$ Paternostro-Sluga et al. ${ }^{21}$ and Wigerstad-Lossing et al. ${ }^{22}$ assessed the isometric quadriceps peak torque. There was a statistically significant difference in favor of ES (MD $-32.70 \mathrm{Nm}$; 95\% CI: -39.92 to -25.48) (Figure 1).

Sisk et al. ${ }^{14}$ assessed the isometric quadriceps peak torque with the knee at seven weeks (MD $0.03 \mathrm{Nm}$; 95\% CI: -0.29 to 0.35 ), eight weeks (MD $-0.07 \mathrm{Nm}$; $95 \% \mathrm{CI}:-0.42$ to 0.28 ) and nine weeks (MD $-0.02 \mathrm{Nm}$; 95\% CI: -0.46 to 0.42 ) after surgery. There were no statistically significant differences between the times assessed. It was not possible to pool the data because of the different dates of isokinetic evaluation. Nine weeks after surgery, the group with ES additionally showed significantly better results for the maximum strength transmitted via the isokinetic system. ${ }^{26}$
Paternostro-Sluga et al. ${ }^{21}$ assessed the quadriceps isometric peak torque at 12 weeks (MD $-14.2 \mathrm{Nm}$; 95\% CI: -16.55 to 44.95) and 52 weeks (MD -20.5 Nm; 95\% CI: -5.49 to 46.49 ) after surgery. There was no statistically significant difference between the groups with and without ES. After one year, Lieber et al. ${ }^{25}$ did not find any significant difference between the groups.

\section{Isokinetic quadriceps peak torque}

At six and eight weeks after surgery, the isokinetic peak torque was assessed at test velocities of $60 \% / \mathrm{s}^{19}$ and $90 \%$ and $210 \% / \mathrm{s} .{ }^{16}$ There was a statistically significant difference in favor of ES at test velocities of $90 \%$ s (MD $-51.20 \mathrm{Nm}$; $95 \% \mathrm{CI}$ : -72.1 to -30.3 ) and of $210 \%$ s (MD $-38.8 \mathrm{Nm}$; 95\% CI: -54.9 to -22.7 ), but not at a test velocity of $60 \%$ s. At 12 weeks (MD $-51.00 \mathrm{Nm}$; 95\% CI: -51 to -10.2 ) and 52 weeks (MD $-26.80 \mathrm{Nm}$; $95 \% \mathrm{CI}$ : -54.51 to 0.91 ) after surgery, Paternostro-Sluga et al. ${ }^{21}$ found that there was no statistical significant difference in quadriceps isokinetic peak torque between the groups. It was not possible to pool the data for this outcome because of the different isokinetic test velocities used and the different assessment times. Buhmann et al. ${ }^{26}$ found that the greatest increase in the group that received ES occurred over the final four weeks of the study. Staub et al. ${ }^{27}$ did not find 
Table 4. Methodological quality of studies included, using Delphi list criteria

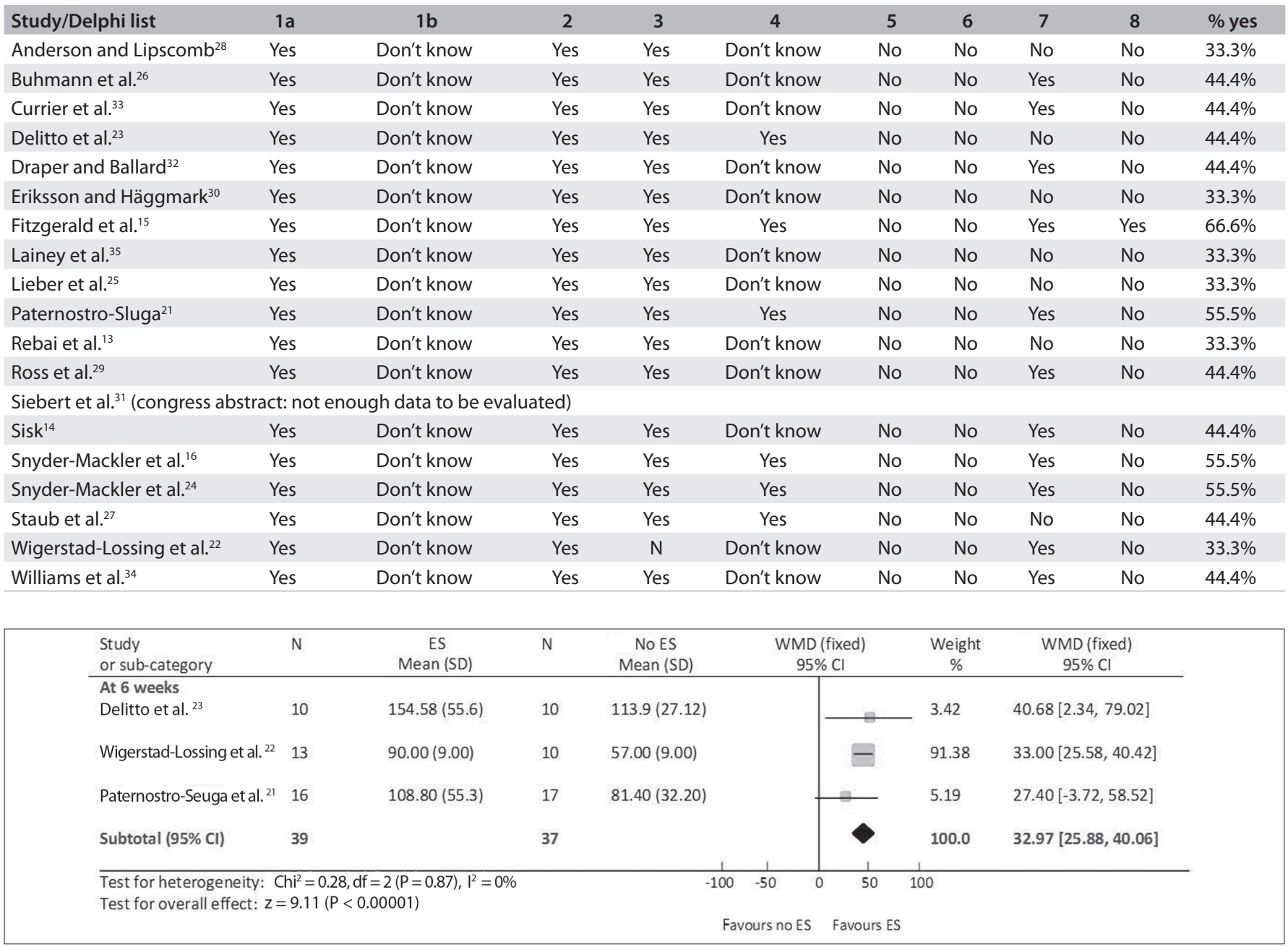

Figure 1. Meta-analysis graph

any statistical significance between the ES group and the control group regarding increases and decreases in isometric peak torque at either 12 weeks or nine months after the operation. At 18 weeks, Anderson and Lipscomb ${ }^{28}$ found a statistically significant difference favoring the ES group.

\section{Isometric quadriceps index}

Two studies ${ }^{15,23}$ assessed the effectiveness of ES using the isometric quadriceps index at six, 12 and 16 weeks after surgery. There was a statistically significant difference in favor of ES six weeks after surgery (MD -27.10\%; 95\% CI: -39.37 to -14.83 ), whereas there was no statistically significant difference at 12 weeks (MD -8.9 Nm; 95\% CI: -19.89 to 2.09) and 16 weeks (MD $-8.10 \mathrm{Nm}$; $95 \% \mathrm{CI}$ : -18.09 to 1.89 ) after surgery. It was not possible to do a meta-analysis because of the different evaluation dates. Snyder-Mackler et al. ${ }^{24}$ found at six weeks after surgery that the quadriceps had achieved $70 \%$ recovery with high-intensity exercise and 57\% with volitional exercise.

\section{Isokinetic quadriceps index}

At eight weeks after surgery, Snyder-Mackler et al. ${ }^{16}$ assessed the isokinetic quadriceps index at two test velocities. There was a statistically significant difference in favor of ES at the test velocities of $90 \%$ s (MD -23.4\%; 95\% CI: -29.32 to -17.48 ) and $210 \%$ (MD $-25.2 \mathrm{Nm}$; $95 \% \mathrm{CI}:-30.07$ to -20.33$)$.

\section{Functional outcomes}

\section{$A D L$ questionnaire}

At 12 and 16 weeks after surgery, Fitzgerald et al. ${ }^{15}$ showed that there was a statistically significant difference in favor of ES in relation to the ADL questionnaire on both occasions (MD -7 $\mathrm{Nm}$; $95 \% \mathrm{CI}:-12.78$ to -1.22 ; and MD $-5.1 \mathrm{Nm}$; $95 \% \mathrm{CI}:-9.74$ to -0.46$)$.

\section{Lysholm score (without correlatable data)}

At 12 weeks and nine months, there was no statistical significance between the ES and control group regarding Lysholm and Tegner scores in the study by Staub et al. ${ }^{27}$ 
Range of motion

At 18 weeks, Anderson and Lipscomb ${ }^{28}$ found a greater range of motion in the ES group (without correlatable data).

\section{Number of participants using crutches}

At four and eight weeks after surgery, Fitzgerald et al. ${ }^{15}$ found that there were no statistically significant differences in the number of participants using crutches.

Number of participants who did not progress to treadmill running Fitzgerald et al..$^{15}$ assessed the number of participants who did not progress to treadmill running and found that there were no statistically significant differences at 12 weeks (RR $0.7 ; 95 \%$ CI: 0.36 to 1.36 ) or 16 weeks (RR 0.45 ; $95 \%$ CI: 0.13 to 1.51 ) after surgery.

\section{Gait analysis}

Gait was assessed in one study. ${ }^{16}$ There were statistically significant differences in favor of ES regarding gait velocity (MD -0.28 $\mathrm{m} / \mathrm{s} ; 95 \% \mathrm{CI}:-0.34$ to -0.22$)$, standing time on the side involved (MD $-6.80 \mathrm{~s} ; 95 \% \mathrm{CI}:-8.92$ to -4.68 ) and cadence (MD -6.10 ; 95\% CI: -8.22 to -3.98$)$.

Fastex test (gait step test, stabilization step test and quick feet test) At 12 weeks and nine months after surgery, Staub et al. ${ }^{27}$ did not find any statistically significant difference between the ES and control group (without correlatable data) in the Fastex test.

\section{Unilateral squat test, lateral step test and forward reach test}

At six weeks after the operation, Ross ${ }^{29}$ did not find any statistical significance between the groups in the unilateral squat test (MD 6.07; 95\% CI: -8.81 to 20.95 ), lateral step test (MD -3.30 s; $95 \%$ CI: -1.20 to 7.80 ) or forward reach test (MD $58.75 \mathrm{~s} ; 95 \% \mathrm{CI}: 0.45$ to 5.90 ).

\section{Knee pain}

Fitzgerald et al. ${ }^{15}$ found that there were no statistically significant differences in knee pain at 12 weeks (MD -0.3; 95\% CI: -0.7 to 1.3 ) or 16 weeks (MD $-0.2 ; 95 \% \mathrm{CI}:-0.89$ to 0.49 ) after the surgery.

\section{Muscle strength (manual muscle test)}

Patients who underwent ES performed better in the manual muscle test than did the control group..$^{30}$

\section{KT-1000 (instrumental stability test)}

Buhmann et al. ${ }^{26}$ did not find any significant differences between the treatment groups (no data presented).

\section{Computed tomography scan}

Siebert et al. ${ }^{31}$ studied patients who underwent knee ligament surgery. At six weeks after the operation, the quadriceps area had become significantly reduced in the control and physical exercise group, in comparison with the group that had exercise combined with electrical stimulation.

\section{Comparison 2: Conventional rehabilitation with ES versus} conventional rehabilitation with biofeedback

One study made this comparison. At six weeks after surgery, Draper and Ballard ${ }^{32}$ found a statistically significant difference in favor of biofeedback regarding the isometric quadriceps index (MD -8.5 Nm; 95\% CI: -16.72 to -0.28 ).

\section{Range of motion}

There was no difference in the range of motion between the two groups at one week (MD 0.4; 95\% CI: -2.12 to 2.92), two weeks (MD -0.6; 95\% CI: -4.43 to 3.23) or four weeks (MD 1.0; 95\% CI: -2.55 to 4.55$)$ after surgery. ${ }^{32}$

Comparison 3: Conventional rehabilitation with ES of $20 \mathrm{~Hz}$ versus conventional rehabilitation with ES of $80 \mathrm{~Hz}$

Isometric quadriceps peak torque

At 12 weeks after surgery, Rebai et al. ${ }^{13}$ found that there was no statistically significant difference between using ES of $20 \mathrm{~Hz}$ and using ES of $80 \mathrm{~Hz}$. After 12 weeks of rehabilitation, the quadriceps peak torque deficit was less than $30 \%$, except for two patients in the $20 \mathrm{~Hz}$ stimulated group (without correlatable data).

\section{Volume deficit}

The thigh muscle volume deficit in the operated limb was between $3 \%$ and $9 \%$ in the $20 \mathrm{~Hz}$ stimulated group and between $1 \%$ and $2 \%$ in the $80 \mathrm{~Hz}$ stimulated group, in the study by Rebai et al. ${ }^{13}$ (without correlatable data).

Comparison 4: Conventional rehabilitation with highintensity ES of $2500 \mathrm{~Hz}$ at a burst rate of $75 \mathrm{~Hz}$ versus conventional rehabilitation with low-intensity ES of $55 \mathrm{~Hz}$

Isometric quadriceps index

Snyder-Mackler et al. ${ }^{24}$ found at six weeks after surgery that the degree of quadriceps recovery was $70 \%$ with high-intensity training and $51 \%$ with low-intensity training (without correlatable data).

\section{Comparison 5: ES versus ES plus pulsed electromagnetic field} Thigh girth

In the study by Currier et al., ${ }^{33}$ at six weeks after surgery, there was no difference between the groups regarding thigh girth measured at $12 \mathrm{~cm}$ (MD $-2.8 \mathrm{~cm}$; 95\% CI: -8.17 to 2.57 ), $20 \mathrm{~cm}$ (MD $-1.6 \mathrm{~cm}$; $95 \% \mathrm{CI}:-7.38$ to 4.18 ) and $25 \mathrm{~cm}$ (MD $-1.4 \mathrm{~cm}$; $95 \%$ CI: -7.21 to 4.41 ) proximally to the superior patellar pole.

\section{Results for meniscectomy patients}

Comparison: Conventional rehabilitation with ES versus conventional rehabilitation 


\section{Isometric quadriceps peak torque}

There was no significant difference between the groups in the study by Williams et al., ${ }^{34}$ at three weeks after meniscectomy (MD $22.3 \mathrm{Nm}$; $95 \%$ CI: -0.1 to 4.47$)$. At six weeks, no differences were found between the groups in the study by Lainey et al. ${ }^{35}$ (without correlatable data).

\section{DISCUSSION}

The studies included did not address all of our objectives. Heterogeneous strength assessment protocols (evaluation data, test position and test speed) need to be standardized in order to compare results from ES studies. The participants in the studies included in this review were patients who underwent surgical reconstruction of the anterior cruciate ligament and meniscectomy, so the results from this review should not be generalized to people with collateral or posterior cruciate ligament injuries.

This review found that muscle strength was higher six weeks after surgery with ES. This finding can be explained by two theories: firstly, a combination of ES and voluntary exercise results in more exercise for the muscle; and secondly, there is preferential activation of type II fibers through ES. Activation of both types of fibers may result in an improvement of strength. Better results from ES over the initial rehabilitation period may be associated with weaker muscles over this period (six to eight weeks after surgery), and an additional stimulus (ES) makes a strong difference. We recommend that ES should be used over the first six weeks after surgery. Based on the studies included, we recommend that the ideal low frequency for increasing muscle strength ranges from 35 to $80 \mathrm{~Hz}$. For cases of medium frequency, the modulation should be at $2500 \mathrm{~Hz} / 50-75 \mathrm{~Hz}$. The pulse duration should be around 200 to 350 microseconds and it is recommended that the relationship between contraction and resting times should be about 1:5 during the early rehabilitation phase.

Functional assessment is extremely important because returning to normal activities is the main goal of rehabilitation. Functional improvements were achieved through the use of ES, in relation to the following outcomes: activities of daily living scale, walking velocity and time spent standing on the injured leg.

One possible limitation of our study is that we carried out just one meta-analysis with only three studies, because of data heterogeneity. For the studies without correlatable data, we made a description of the results.

We carried out a literature search in which we placed importance on the quality aspects of the studies. The Consolidated Standards for Reporting Trials (CONSORT) Statement is a checklist of items that the reports on clinical trials must follow. The CONSORT Statement, ${ }^{36}$ which was created in 1999 and updated in 2010, aims to improve reports on randomized clinical trials, help authors to recognize suitable study designs and assess study validity. Most of the studies included in this review did not follow the precepts of the CONSORT Statement: there was no reporting of allocation concealment in any study; none of them reported sample size calculation; and, of the studies with drop-outs, only one mentioned intention-to-treat analysis. Using the Delphi list to assess the studies, the studies were found to fulfill at least half of the items: the groups of patients were similar at the baseline; all the inclusion criteria were well described; all the studies were randomized; and, in three studies, the assessor was blinded.

A systematic review published in $2005^{37}$ assessed the effectiveness of ES on the quadriceps muscles of both healthy and injured individuals. The present study focused only on injured individuals and, in addition to strength, we reported knee function outcomes. In contrast to Bax et al., ${ }^{37}$ we included only randomized controlled clinical trials. One of the conclusions of the previous systematic review was that ES might be more effective than voluntary exercises on weakened muscles. Our review agrees with another systematic review published in $2010,{ }^{38}$ which included eight studies and concluded that ES combined with exercise might be more effective in improving quadriceps strength than exercise alone and that inconsistencies were noted in the ES parameters and their application.

\section{CONCLUSION}

The evidence available from randomized clinical trials of limited quality shows that electrical stimulation, in combination with a conventional rehabilitation program, might be more effective for improving muscle strength and function for up to two months after ACL reconstruction than conventional rehabilitation alone.

\section{Implications for research}

Randomized controlled trials of better methodological quality, with adequate sample size and with at least 12 months of follow-up are necessary to ascertain the effectiveness of ES for increasing the muscle strength of patients with soft tissue injuries of the knee.

\section{REFERENCES}

1. Thomson LC, Handoll HH, Cunningham A, Shaw PC. Physiotherapistled programmes and interventions for rehabilitation of anterior cruciate ligament, medial collateral ligament and meniscal injuries of the knee in adults. Cochrane Database Syst Rev. 2002;(2):CD001354

2. Irvine GB, Glasgow MM. The natural history of the meniscus in anterior cruciate insufficiency. Arthroscopic analysis. J Bone Joint Surg Br. 1992;74(3):403-5.

3. Binfield PM, Maffulli N, Good CJ, King JB. Arthroscopy in sporting and sedentary children and adolescents. Bull Hosp Jt Dis. 2000; 59(3):125-30. 
4. Arvidsson I, Eriksson E, Häggmark T, Johnson RJ. Isokinetic thigh muscle strength after ligament reconstruction in the knee joint: results from a 5-10 year follow-up after reconstructions of the anterior cruciate ligament in the knee joint. Int J Sports Med. 1981;2(1):7-11.

5. Seto JL, Orofino AS, Morrissey MC, Medeiros JM, MasonWJ. Assessment of quadriceps/hamstring strength, knee ligament stability, functional and sports activity levels five years after anterior cruciate ligament reconstruction. Am J Sports Med. 1988;16(2):170-80.

6. Tibone JE, Antich TJ. A biomechanical analysis of anterior cruciate ligament reconstruction with the patellar tendon. A two year followup. Am J Sports Med. 1988;16(4):332-5.

7. Häggmark T, Jansson E, Eriksson E. Fiber type area and metabolic potential of the thigh muscle in man after knee surgery and immobilization. Int J Sports Med. 1981;2(1):12-7.

8. Halkjaer-Kristensen J, Ingemann-Hansen T. Wasting of the human quadriceps muscle after knee ligament injuries. Scand J Rehabil Med Suppl. 1985;13:5-55.

9. Morrissey MC, Brewster $C E$, Shields $C L$ Jr, Brown M. The effects of electrical stimulation on the quadriceps during postoperative knee immobilization. Am J Sports Med. 1985;13(1):40-5

10. Perry J, Fox JM, Boitano MA, et al. Functional evaluation of the pes anserinus transfer by electromyography and gait analysis. J Bone Joint Surg Am. 1980;62(6):973-80.

11. Gerber C, Hoppeler H, Claassen H, et al. The lower-extremity musculature in chronic symptomatic instability of the anterior cruciate ligament. J Bone Joint Surg Am. 1985;67(7):1034-43.

12. Vegso JJ, Genuario SE, Torg JS. Maintenance of hamstring strength following knee surgery. Med Sci Sports Exerc. 1985;17(3):376-9.

13. Rebai $H$, Barra V, Laborde A, et al. Effects of two electrical stimulation frequencies in thigh muscle after knee surgery. Int J Sports Med. 2002;23(8):604-9.

14. Sisk TD, Stralka SW, Deering MB, Griffin JW. Effect of electrical stimulation on quadriceps strength after reconstructive surgery of the anterior cruciate ligament. Am J Sports Med. 1987;15(3):215-20.

15. Fitzgerald GK, Piva SR, Irrgang JJ. A modified neuromuscular electrical stimulation protocol for quadriceps strength training following anterior cruciate ligament reconstruction. J Orthop Sports Phys Ther 2003;33(9):492-501.

16. Snyder-Mackler L, Ladin Z, Schepsis AA, Young JC. Electrical stimulation of the thigh muscles after reconstruction of the anterior cruciate ligament. Effects of electrically elicited contraction of the quadriceps femoris and hamstring muscles on gait and on strength of the thigh muscles. J Bone Joint Surg Am. 1991;73(7):1025-36.

17. Robinson AJ, Snyder-Mackler L. Clinical electrophysiology: electrotherapy and electrophysiologic testing. $2^{\text {nd }}$ ed. Baltimore: Lippincott Williams \& Wilkins; 1995.

18. Verhagen AP, de Vet HC, de Bie RA, et al. The Delphi list: a criteria list for quality assessment of randomized clinical trials for conducting systematic reviews developed by Delphi consensus. J Clin Epidemiol. 1998;51(12):1235-41.
19. FrankeJ,UIImannP,SchleicherW.Wirksamkeit derElektromyostimulation (EMS) nach Operationen am Kapsel-Band-Apparat des Kniegelenkes bei Sportlern [The effectiveness of electromyostimulation following operations of the capsule-ligament system of the knee joint in athletes]. Sportverletz Sportschaden. 1989;3(2):62-6.

20. Hörster G, Kedziora O. Kraftverlust und -regeneration der Kniestreckmuskulatur nach Operationen am Kniebandapparat. EMG-Untersuchungen zum Einfluss von Verletzungsmuster, Operationsverfahren und Nachbehandlung unter besonderer Berücksichtigung der EMS [Loss of strength and regeneration of knee extensor musculature after operations of the knee ligaments. EMG studies of the effect of the injury pattern, surgical procedure and after-care with special reference to electromyostimulation]. Aktuelle Traumatol. 1993;23(5):244-54.

21. Paternostro-Sluga T, Fialka C, Alacamliogliu Y, Saradeth T, FialkaMoser V. Neuromuscular electrical stimulation after anterior cruciate ligament surgery. Clin Orthop Relat Res. 1999;(368):166-75.

22. Wigerstad-Lossing I, Grimby G, Jonsson T, et al. Effects of electrical muscle stimulation combined with voluntary contractions after knee ligament surgery. Med Sci Sports Exerc. 1988;20(1):93-8.

23. Delitto A, Rose SJ, McKowen JM, et al. Electrical stimulation versus voluntary exercise in strengthening thigh musculature after anterior cruciate ligament surgery. Phys Ther. 1988;68(5):660-3.

24. Snyder-Mackler L, Delitto A, Bailey SL, Stralka SW. Strength of the quadriceps femoris muscle and functional recovery after reconstruction of the anterior cruciate ligament. A prospective, randomized clinical trial of electrical stimulation. J Bone Joint Surg Am. 1995;77(8):1166-73.

25. Lieber RL, Silva PD, Daniel DM. Equal effectiveness of electrical and volitional strength training for quadriceps femoris muscles after anterior cruciate ligament surgery. J Orthop Res. 1996;14(1):131-8.

26. BuhmannHW, SchleicherW, UrbachD, SchultzW.Elektromyostimulation und isokinetisches Training in der Rehabilitation nach Operationen des vorderen Kreuzbandes - eine randomisierte, prospektive Studie [Electromyostimulation and isokinetic training in rehabilitation after anterior cruciate surgery]. Physikalische Medizin Rehabilitationsmedizin Kurortmedizin. 1998;8(1):13-6. Available from: https://www.thiemeconnect.com/ejournals/abstract/physmed/doi/10.1055/s-20081061813. Accessed in 2011 (Apr 26).

27. Staub A, Ullmann P, Winker KH. Die Elektromyostimulation bei frühfunktioneller Rehabilitation nach vorderer Kreuzbandersatzplastik [Electromyostimulation under Early Rehabilitation after Replacement of the Anterior Cruciate Ligament\}. Sporttraumatologie Akt Traumatol. 2002;32(2):65-72. Available from: https://www.thieme-connect.com/ ejournals/abstract/trauma/doi/10.1055/s-2002-25750. Accessed in 2011 (Apr 26).

28. Anderson AF, Lipscomb AB. Analysis of rehabilitation techniques after anterior cruciate reconstruction. Am J Sports Med. 1989;17(2):154-60.

29. Ross M. The effect of neuromuscular electrical stimulation during closed kinetic chain exercise on lower extremity performance 
following anterior cruciate ligament reconstruction. Research in Sports Medicine: An International Journal. 2000;9(4):239-51. Available from: http://www.informaworld.com/smpp/content db=all conte nt=a913026809. Accessed in 2011 (Apr 26).

30. Eriksson E, HäggmarkT. Comparison of isometric muscle training and electrical stimulation supplementing isometric muscle training in the recovery after major knee ligament surgery. A preliminary report. Am J Sports Med. 1979;7(3):169-71.

31. SiebertWE, Kohn D, Wirth CJ. Influence of electrical muscle stimulation on postoperative muscle atrophy after major knee ligament surgery. International Journal of Sports Medicine. 1988;5(9):376. [abstract].

32. Draper V, Ballard L. Electrical stimulation versus electromyographic biofeedback in the recovery of quadriceps femoris muscle function following anterior cruciate ligament surgery. Phys Ther. 1991;71(6):455-61; discussion 461-4.

33. Currier DP, Ray JM, Nyland J, et al. Effects of electrical and electromagnetic stimulation after anterior cruciate ligament reconstruction. J Orthop Sports Phys Ther. 1993;17(4):177-84.

34. Williams RA, Morrissey MC, Brewster CE. The effect of electrical stimulation on quadriceps strength and thigh circumference in menisectomy patients. J Orthop Sports Phys Ther. 1986;8(3):143-6.

35. Lainey CG, Walmsley RP, Andrew GM. Effectiveness of exercise alone versus exercise plus electrical stimulation in strengthening the quadriceps muscle. Physiotherapy Canada. 1983;35(1):5-11.

36. Atallah AN, Castro AA. Uniform requirements for manuscripts, CONSORT statement and more informative abstracts: three fundamental papers for improving the quality of medical publications. Sao Paulo Med J. 1999;117(1):3-4.

37. Bax L, Staes F, Verhagen A. Does neuromuscular electrical stimulation strengthen the quadriceps femoris? A systematic review of randomised controlled trials. Sports Med. 2005;35(3):191-212.

38. Kim KM, Croy T, Hertel J, Saliba S. Effects of neuromuscular electrical stimulation after anterior cruciate ligament reconstruction on quadriceps strength, function, and patient-oriented outcomes: a systematic review. J Orthop Sports Phys Ther. 2010;40(7):383-91.

\section{Sources of funding: None}

Conflict of interest: None

Date of first submission: December 23, 2010

Last received: May 9, 2011

Accepted: May 23, 2011

\section{Address for correspondence:}

Aline Mizusaki Imoto de Oliveira

Rua Pedro de Toledo, 598

Vila Clementino — São Paulo (SP) — Brasil

CEP 04039-001

Tel. (+55 11) 5575-2970

E-mail: aline.mizusaki@globo.com 